\title{
MAXIMAL NUMERICAL RANGE OF A COMPACT SET AND APPLICATIONS TO SOME DRAGOMIR'S INEQUALITIES
}

\author{
ABDERRAHIM BAGHDAD AND MOHAMED CHRAIBI KAADOUD
}

Abstract. Let $K, A$ be respectively a compact and an element of $B(H)$ the algebra of all bounded linear operators acting on a complex Hilbert space $H$. In this paper we define the maximal numerical range of the set $A^{*} K=\left\{A^{*} B: B \in K\right\}$ relatively to $K$ by

$$
W_{K}\left(A^{*} K\right)=c o\left(\bigsqcup_{B \in K} W_{B}\left(A^{*} B\right)\right) .
$$

Where $W_{B}\left(A^{*} B\right)$ is the maximal numerical range of $A^{*} B$ relatively to $B$ defined by Magajna [6] and which coincides with the maximal numerical range $W_{0}(B)$ of $B$ defined by Stampfli [7] if $A$ is the unit element $I$. Our new definition will generalize the results of Stampfli [7] and BarraaBoumazguour [1] over the distance of an element $B$ to $\operatorname{Vect}(A)$. It also will generalize and improve several inequalities established by Dragomir $[4,5]$ linking the norm and the numerical radius of $B$.

Mathematics subject classification (2010): 47A05, 47A12, 47A30.

Keywords and phrases: Distance to scalars, norm, numerical range, maximal numerical range, numerical radius and center of mass.

\section{REFERENCES}

[1] M. BARRAA, M. BoumAZgour, A note on the orthogonality of bounded linear operators, Functional Analysis, Approximation and Computation, 4: 1 (2012), 65-70.

[2] A. Bouchen, M. Chraibi KaAdoud, Spectrum and Numerical Range of a Compact Set, Extracta Mathematicae, Vol. 28, Núm. 1, 13-31 (2013).

[3] M. Chraibi KAADOUd, Géométrie du spectre dans une algèbre de Banach et domaine numérique, Stud. Math. 161, 1 (2004), 1-14.

[4] S. S. DRAGOMiR, Norm and numerical radius inequalities for a product of tow linear operators in Hilbert spaces, J. Math. Inequal. 2 (2008), no. 4, 499-510.

[5] S. S. DRAGOMIR, Inequalities for the norm and the numerical radius of composite operators in Hilbert spaces, Inequalities and applications, 135-146, Internat. Ser. Numer. Math., Birkhäuser, Basel, 2009.

[6] B. Magajna, On the distance to finite dimentional suspaces in operator algebras, J. London. Math. Soc. 47 (1993), 516-532.

[7] J. Stampfli, The norm of derivation, Pacific Journal of Mathematics, Vol. 33, no. 3, 1970. 